\title{
Levorphanol in the Perioperative Setting: Decreasing Opioid Requirements While Improving Pain Management
}

This article was published in the following Dove Press journal:

Journal of Pain Research

\section{Christopher R Page \\ Carlos Andres Perez \\ Ana Mavarez-Martinez \\ Sara Khan \\ Sergio D Bergese (D)}

Department of Anesthesiology, Stony Brook University Hospital, Stony Brook, NY, USA
Correspondence: Christopher R Page Email christopher.

page@stonybrookmedicine.edu

\begin{abstract}
Levorphanol is a Food and Drug Administration (FDA)-approved long-acting opioid. Most information on perioperative use of levorphanol comes from the early- and mid1950s when this drug emerged in the field of experimental pharmacology and anesthesia. It was mainly studied during this period with some additional data being generated in the 1960s and 70s. Since this time, perioperative use has declined and research is limited. This review of literature aims to provide pharmacologic and historic description of levorphanol as a tool for perioperative pain management and as an aid to potentially decrease total postoperative opioid use during the current opioid crisis.
\end{abstract}

Keywords: levorphanol, methadone, long-acting opioid, perioperative analgesia

\section{Introduction}

Surgery and associated tissue damage cause pain during and after a procedure. Opioids have been one of the most common medications employed to provide postoperative analgesia. Approximately 5.9 to $6.5 \%$ of patients receiving perioperative opioids in the hospital setting are more likely to continue opioid consumption after surgery. ${ }^{1}$

Opioid use after discharge from the hospital has been linked to factors such as young age and opioid consumption the day before discharge. ${ }^{2}$ The American Society for Enhanced Recovery and Perioperative Quality Initiative Joint Consensus Statement on Perioperative Opioid Minimization in Opioid-Naïve Patients, has suggested that adequate pain management focused on reduction of inpatient opioid use may limit post-discharge opioid prescribing and help in the prevention of chronic opioid consumption. ${ }^{3}$

Attempts to reduce the risk of long-term opioid use include the implementation of perioperative multimodal analgesia and opioid-free anesthesia. ${ }^{4}$ Opioid-free anesthesia has been associated with decreased opioid use in the post-anesthesia care unit (PACU) but with limited reduction of opioid consumption by 6 hours postsurgery. ${ }^{5-7}$ A concrete and thorough breakdown of opioid-free anesthetic practice benefit/risk profile has not been adequately completed. ${ }^{3}$

Long-acting opioids, including levorphanol and methadone have been utilized in the past to provide extended perioperative analgesia, reducing total postoperative opioid requirements. Levorphanol is therefore a useful option for post-operative opioid reduction while still providing the inherent benefits of opioid analgesia. ${ }^{8-12}$ Levorphanol also 
has superior pharmacological properties that make it ideal for inclusion as part of multimodal analgesia regimens and enhanced recovery after surgery (ERAS) pathways.

The purpose of this review article is to provide a pharmacologic and historic description of levorphanol as a tool for perioperative pain management and as an aid to limit additional postoperative opioid requirements. We also compared pharmacological similarities between levorphanol and methadone, aiming to demonstrate which long-term opioid may be more beneficial for use in the perioperative setting.

\section{Methods}

A review of literature including the keywords "levorphanol" AND "operative" was performed. PubMed, Medline, and Google Scholar databases were searched. A total of 841 results were obtained and reduced to 242 filtering use in human subjects alone. A total of 10 articles with full text on perioperative use of levorphanol were found (Table 1) and included a World Health Organization bulletin with multiple references on the use of levorphanol in perioperative settings. A narrative voice was used given the limited sample size and variety in study designs. Other supporting literature was included as an adjunct to help broaden the understanding and evolution of the use of this medication, its pharmacological properties and the importance and potential of further research.

\section{Levorphanol: Pharmacologic Characteristics}

Dromoran (racemorphan), is the racemic mixture of 3-hydroxy-methyl morphinan and includes both the levoand dextro- isomers. Levorphanol is the levo-isomer of racemorphan (dromoran) and is the compound responsible for the majority of analgesia and respiratory depression. ${ }^{13}$ It is a phenanthrene structure and is similar to morphine but lacks a 6-hydroxyl and oxygen group. ${ }^{14}$ Levallorphan is the dextro-isomer and is mostly devoid of these properties. $^{15}$

Levorphanol has activity at multiple analgesic relevant receptors. It is an agonist at the $\mu, \delta$, and $\kappa$ opioid receptors and a non-competitive antagonist at the N-methyl-d aspartate (NMDA) receptor as well as inhibiting serotonin and norepinephrine reuptake. It has analgesic effects via intramuscular (IM), intravenous (IV), subcutaneous (SC) and oral route of administration. Analgesia occurs after one hour (oral), 20 minutes (IV), and 15 to 30 minutes (IM). ${ }^{14}$ Half-life varies according to route of administration, ranging from 11 to 30 hours via parental and oral route, respectively. ${ }^{14,16}$ Analgesic effect has been described to last approximately 6-15 hours. ${ }^{14,16,17}$ Metabolism of levorphanol occurs via hepatic glucuronidation, producing levorphanol-3-glucornin. An inactive metabolite is slowly eliminated mainly via renal excretion and does not contribute to the analgesia efficacy of levorphanol. ${ }^{18}$ There is no cytochrome P450 system involvement in this process, limiting drug-drug interaction. ${ }^{19}$

\section{Levorphanol Use in the Perioperative Setting Preoperative Use}

In 1954, Brown et al used levorphanol as premedication in 100 patients undergoing gynecological or general surgery. Levorphanol $2 \mathrm{mg}$ alone was used in 30 patients, levorphanol $2 \mathrm{mg}+$ atropine $0.65 \mathrm{mg}$ in 20 patients, and levorphanol + scopolamine in 50 patients. Adequate premedication was obtained in $63-85 \%$ of the study population. ${ }^{20}$ In this same year, Starke et al assessed the use of $2 \mathrm{mg}$ of levorphanol via subcutaneous administration as premedication in 800 patients undergoing rhino-laryngology operative procedures and discussed its use to be "mostly" effective. $^{15,21}$

In 1969, eleven analgesic medications including levorphanol were compared as premedication under a blinded protocol. Female patients undergoing minor gynecologic procedures were randomized to receive different synthetic opioids including levorphanol $2 \mathrm{mg}$, methadone $10 \mathrm{mg}$, and fentanyl $0.2 \mathrm{mg}$, among others. Assessment of efficacy and side effects were documented in the pre-anesthetic stage at 60 and 90 minutes after administration and up to 6 hours post-operatively. Levorphanol was ranked first in this study as premedication (for both drowsiness and calming effect) and had a superiorly ranked safety profile for avoiding toxic side effects when compared to methadone and fentanyl. ${ }^{22}$

A subsequent publication from the same authors further expanded the comparison of opioid analgesics. ${ }^{23}$ Data was collected over a period of 7 years and 17 opiates were analyzed in efficacy, toxicity, and postoperative emetic sequelae in similar population and surgical characteristics. All medications were used at what was considered to be equipotent doses. Data analysis was applied to rank medications according to effectiveness as premedication. Levorphanol once again positioned itself at the top of the list ranked second for efficacy as premedication, surpassed 
Table I Overview of Studies Using Levorphanol in the Perioperative Setting

\begin{tabular}{|c|c|c|c|c|c|}
\hline Study & Indication & $\mathbf{N}$ & Dosage & $\begin{array}{l}\text { Analgesic Effect/Premedication } \\
\text { Outcome }\end{array}$ & Side Effects \\
\hline Brown et al $(1954)^{20}$ & Premedication & 100 & $2 \mathrm{mg}$ & Premedication successful in $67-85 \%$ & $\begin{array}{l}\text { Respiratory depression in } \\
0-6 \% \text {, nausea in } 0-15 \%\end{array}$ \\
\hline Starke et al $(1954)^{21}$ & Premedication & 800 & $2 m g$ & "Mostly effective" & $\begin{array}{l}\text { "dizziness, nausea, vomiting < } \\
\text { morphine" }\end{array}$ \\
\hline $\begin{array}{l}\text { Morrison et al } \\
(1969)^{22}\end{array}$ & Premedication & 100 & $2 m g$ & Ranked \#I as premedication & $\begin{array}{l}\text { Ranked better in safety profile } \\
\text { (less side effects) than } \\
\text { methadone and fentanyl }\end{array}$ \\
\hline Brown et al $(1954)^{20}$ & $\begin{array}{l}\text { Intraoperative } \\
\text { Medication }\end{array}$ & 25 & $\begin{array}{l}\text { "continuous } \\
\text { drip" }\end{array}$ & Not mentioned & $\begin{array}{l}\text { Severe respiratory depression } \\
\text { was found }\end{array}$ \\
\hline Dundee et al $(1969)^{8}$ & $\begin{array}{l}\text { Intraoperative } \\
\text { Medication }\end{array}$ & 67 & $2 \mathrm{mg}$ & $\begin{array}{l}82 \% \text { of patients required no analgesia } \\
6 \text { hours postop }\end{array}$ & $\begin{array}{l}\text { Respiratory depression was } \\
\text { seen in I case }\end{array}$ \\
\hline $\begin{array}{l}\text { McDowell et al } \\
(1971)^{9}\end{array}$ & $\begin{array}{l}\text { Intraoperative } \\
\text { Medication }\end{array}$ & 25 & $2 m g$ & $\begin{array}{l}\text { Mean time to postoperative } \\
\text { analgesic requirement was longest ( } 9 \\
\text { hours) and mean postoperative } \\
\text { opioid requirements were least in } \\
\text { the levorphanol group. }\end{array}$ & $\begin{array}{l}\text { "heart rate and blood pressure } \\
\text { were more stable when } \\
\text { levorphanol was used" }\end{array}$ \\
\hline $\begin{array}{l}\text { Glazebrook et al } \\
(1952)^{27}\end{array}$ & $\begin{array}{l}\text { Post- } \\
\text { Operative Pain }\end{array}$ & $\begin{array}{l}200(14 \\
\text { post-op } \\
\text { pain) }\end{array}$ & $1.3-4 \mathrm{mg}$ & $\begin{array}{l}\text { "Will control postoperative pain as } \\
\text { well or better than morphine." }\end{array}$ & $\begin{array}{l}\text { Not specified to the } 14 \text { cases of } \\
\text { postop pain }\end{array}$ \\
\hline Hunt et al $(1953)^{10}$ & $\begin{array}{l}\text { Post- } \\
\text { Operative Pain }\end{array}$ & 311 & $3 \mathrm{mg}$ & $\begin{array}{l}\text { Effective analgesia obtained in } 97 \% \text { of } \\
\text { patients }\end{array}$ & $\begin{array}{l}\text { Side effects were less in } \\
\text { levorphanol group vs morphine } \\
\text { group }\end{array}$ \\
\hline Brown et al $(1954)^{20}$ & $\begin{array}{l}\text { Post- } \\
\text { Operative Pain }\end{array}$ & "several" & $2+m g$ & $\begin{array}{l}\text { Found to provide an average of } 7 \\
\text { hours of postoperative pain relief, } \\
\text { once } 4 \mathrm{mg} \text { had been administered, } \\
\text { relief of pain could be maintained } \\
\text { with the use of } 0.5 \mathrm{mg} \text { every } 12 \\
\text { hours }\end{array}$ & Not mentioned \\
\hline \multirow[t]{2}{*}{ Rankin et al $(1957)^{17}$} & $\begin{array}{l}\text { Post- } \\
\text { Operative Pain }\end{array}$ & 27 & $2 \mathrm{mg}$ & $\begin{array}{l}\text { Slight or no pain in the first } 6 \text { hours } \\
\text { was documented in } 94.5 \% \text {, average } \\
\text { duration of analgesia was } 10.1 \text { hours. }\end{array}$ & \\
\hline & & 50 & $4-5 \mathrm{mg}$ & & $\begin{array}{l}\text { Nausea in } 22 \% \text {, Emesis in } 8 \% \text { of } \\
\text { levorphanol } 4-5 \mathrm{mg}\end{array}$ \\
\hline $\begin{array}{l}\text { Morrison et al } \\
(1971)^{11}\end{array}$ & $\begin{array}{l}\text { Post- } \\
\text { Operative Pain }\end{array}$ & 40 & $2 \mathrm{mg}$ & $\begin{array}{l}\text { Levorphanol at a dose of } 2 \mathrm{mg} \text { clearly } \\
\text { emerged as the most effective agent } \\
\text { in this trial }\end{array}$ & $\begin{array}{l}\text { Lower incidence of drowsiness } \\
\text { than with morphine }\end{array}$ \\
\hline Banister et al $(1974)^{28}$ & $\begin{array}{l}\text { Post- } \\
\text { Operative Pain }\end{array}$ & 86 & $2 \mathrm{mg}$ & $\begin{array}{l}\text { Statistically equivalent to other } \\
\text { medications }\end{array}$ & $\begin{array}{l}\text { Restlessness, vomiting, euphoria } \\
\text { and dizziness were rarely } \\
\text { induced by any of the drugs and } \\
\text { never exceeded an incidence of } \\
8 \% .\end{array}$ \\
\hline
\end{tabular}


only by diamorphine (heroin). Fentanyl and methadone were positioned at fifth and ninth place, respectively.

Literature seems to indicate that levorphanol can be used as premedication. It has been shown to decrease apprehension while providing a desired drowsiness and analgesia. ${ }^{20-24}$ When analyzing levorphanol as premedication, one must be aware of patient preferences. Levorphanol's success as a premedication stems from the reasoning that drowsiness is a desired effect which may differ among patients and the treating anesthesia personnel.

\section{Intraoperative Use}

In 1954, Crehan et al assessed the use of $0.5-1 \mathrm{mg}$ levorphanol in 252 patients as a supplement to thiopentone/ nitrous oxide anesthesia. They found no respiratory depression except for one case of apnea lasting 30 minutes after an IV administration of $2 \mathrm{mg}$ of levorphanol. ${ }^{15,25}$ Descriptions of levorphanol as a continuous infusion during anesthesia is described by Brown et al in 25 patients and showed significant respiratory depression when used in this manner further stating it is contraindicated for use in this manner. ${ }^{20}$ Postoperative analgesia was not reported for these studies.

In 1969, Dundee et al investigated the use of levorphanol as IV analgesic supplementation for anesthesia during a variety of surgical procedures. A total of 67 pairs of patients with similar demographic and medical characteristics undergoing analogous surgical interventions were compared. Premedication, induction and maintenance of anesthesia were identical in the pairs and addition of levorphanol $2 \mathrm{mg}$ IV following induction was randomized to one patient in each pair. Postoperative analgesia was given when needed using 5-10mg of methadone IM or IV and requirements were documented for all patients. In this pairs study, results showed the most significant difference was the longer time to first postoperative analgesic requirement in the levorphanol group. Additionally, $82 \%$ of levorphanol patients required no analgesia in the first 6 hours postop with average time to first analgesic being approximately 7 hours. Overall postoperative opioid requirement was lower in the levorphanol group. ${ }^{8}$

In 1971 , levorphanol $2 \mathrm{mg}$ was used intraoperatively as part of a standard technique for anesthesia in an institution. A study comparing this method against different modalities of neuroleptic anesthesia in patients undergoing cardiac, thoracic and major abdominal surgery was performed. Standard premedication with 50mg meperidine and $0.6 \mathrm{mg}$ of atropine was given to all subjects followed by induction according to the four modalities of anesthesia being studied: 1) levorphanol, 2) fentanyl, 3) fentanyl +droperidol, and 4) droperidol/fentanyl mixture. Supplemental doses were given intraoperatively as needed according to the group assigned: 1) levorphanol $0.1 \mathrm{mg}, 2$ ) fentanyl $0.1 \mathrm{mg}, 3$ ) fentanyl $0.1 \mathrm{mg}$ and droperidol, and 4) droperidol/fentanyl mixture, respectively. Results showed that fentanyl group was significantly inferior when compared to the levorphanol group. Mean time to postoperative analgesic requirement was longest ( 9 hours) and mean postoperative opioid requirements were least in the levorphanol group. 9

Available literature provides evidence to support the use of levorphanol as an effective intraoperative analgesic during general anesthesia, providing enhanced and prolonged analgesia. ${ }^{8,9,26}$ Most studies describe giving levorphanol at a dose of $2 \mathrm{mg}$ immediately after induction usually via SC or IV bolus with supplemental doses throughout surgery when needed. Levorphanol as a continuous infusion is not recommended since it has been associated with high incidence of respiratory depression. ${ }^{20}$ Patients receiving intraoperative levorphanol demonstrated longer postoperative analgesia ( 7 to 9 hours after emergence) and less postoperative opioid requirements. $^{8,9}$

\section{Postoperative Use}

In 1952, Glazebrook described the use of levorphanol in 200 patients from a variety of diseases, 14 of which were cases of postoperative amputation pain. Analgesia was achieve successfully in $79.5 \%$ of the study population. The levorphanol dose given was 1.3 to $4 \mathrm{mg}$, relieving pain for up to 8 to 14 hours. The author mentioned that levorphanol "will control postoperative pain as well or better than morphine" and concluded that for relief of pain it "may be found superior to morphine". 27

Hunt et al studied 311 patients who had undergone a wide variety of surgical procedures and compared the effect of postoperative analgesia of levorphanol $3 \mathrm{mg}$ via $\mathrm{SC}$ administration to morphine $10 \mathrm{mg}$. Pain was recorded after administration of the assigned medication and was classified as complete, moderate, slight, and none. Pain was documented after the administration of the first and subsequent doses. For the levorphanol group, the average number of doses per patient was 1.8 for the first 24 hours and 3.4 for the subsequent doses; effective analgesia (complete and moderate) was achieved in $97 \%$ of the patients 
with the first dose and in 95\% with subsequent dosing. Compared to patients in the morphine group, where effective analgesia with the first dose and subsequent dosing was achieved in $78 \%$ and $85 \%$, respectively. Duration of analgesia after dosing was reported to be 5.5 hours in patients receiving levorphanol. Side effects such as dizziness, diaphoresis, nausea and emesis were documented to be less in the levorphanol group. ${ }^{10}$

A study performed in 1954 found that levorphanol 2mg given IV provided an average of 7 hours of postoperative pain relief and that after $4 \mathrm{mg}$ had been administered, relief of pain could be maintained with the use of $0.5 \mathrm{mg}$ every 12 hour. $^{20}$

In 1957, the effects of levallorphan on levorphanol analgesia were studied in 77 patients that had undergone pulmonary resection for tuberculosis. Levorphanol $2 \mathrm{mg}$ was administered in 27 patients and $4-5 \mathrm{mg}$ in 50 patients. Both groups were administered levorphanol with or without levallorphan subcutaneously in a blinded and alternating manner. All other analgesics were stopped and pain was documented every 30 minutes for at least 6 hours. Duration of analgesia was recorded from drug administration time until request for more medication. Slight or no pain within the first 6 hours was documented in $94.5 \%$ of all patients who received levorphanol alone with an average duration of analgesia lasting 10.1 hours. $60 \%$ of patients who received levorphanol 4-5mg reported duration of analgesia superior to 9 hours. ${ }^{17}$

In 1971, a 4-year-long study comparing thirteen analgesic drugs given alone or in combination for patients undergoing upper or lower abdominal surgery was published by Morrison et al Postoperative medications including levorphanol $2 \mathrm{mg}$, methadone $10 \mathrm{mg}$, morphine $10 \mathrm{mg}$ and $15 \mathrm{mg}$, fentanyl $0.1 \mathrm{mg}$ and $0.2 \mathrm{mg}$, oxycodone $10 \mathrm{mg}$, and dihydrocodeine $50 \mathrm{mg}$ were given in a randomized double-blinded manner once analgesia was required. Doses of medication were compared at what was believed to be equipotent in terms of causing respiratory depression. Medications were then ranked in order with respect to incidence of successful postoperative pain relief. ${ }^{11}$

Pain was assessed before and after the administration of medication and was scored based on the following criteria: Patient's subjective estimate, observer's subjective estimate, and patient's retrospective estimate of improvement. Additionally, if surgery was upper abdominal then additional measurement of vital capacity and peak expiratory flow were measured. A positive result for analgesia was recorded only if patient's and observer's subjective estimate of decrease in pain coincided with an improvement in vital capacity and peak expiratory flow rate. ${ }^{11}$ The use of levorphanol in this study was associated with successful analgesia in a greater percentage of patients when compared to the other analgesics.

In 1974, Banister et al assessed six analgesic drugs (including levorphanol) for their efficacy in producing relief of postoperative pain. A total of 572 adult patients undergoing minor and intermediate orthopedic procedures were included. Patients were given one of six analgesics intramuscularly when reporting pain in the postoperative period. Dose was adjusted to weight and pain was assessed by patient and observer subjective estimate on a 5-point scale. Data was recorded at 0 and 60 mins after injection. Levorphanol, although not the highest ranked medication in this trial, (when compared in efficacy to pethidine, papaveretum, phenoperidine, pentazocine and piritramide) decreased pain scores to none or slight residual pain in $79 \%$ of the cases which was statistically similar to all other medications in the study. ${ }^{28}$

Other studies mentioned by the World Health Organization report include Emmons et al who used levorphanol $2 \mathrm{mg} \mathrm{SC}$ or $3 \mathrm{mg}$ oral administration with effective analgesia being obtained in $96 \%$ and $74 \%$ of patients respectively. Bozza et al and Senne et al report obtaining analgesia ranging from 6-15 hours using an average of $2 \mathrm{mg}$ of levorphanol via SC administration. Gaard et al describes postoperative analgesia as being "mostly satisfactory" with the use of $2 \mathrm{mg}$ subcutaneous levorphanol. ${ }^{15}$

Postoperative administration of levorphanol is the broadest documented perioperative period of use. In general, the use of postoperative levorphanol was associated with longer and more effective analgesia with overall less opioid requirements when compared to other medications including methadone and morphine. ${ }^{10,11,27}$

Doses varied throughout these studies, yet $2 \mathrm{mg}$ seems to be the most frequently adopted dose resulting in adequate pain relief. SC dosing with $2 \mathrm{mg}$ is most common and may yield analgesia up to 15 hours, ${ }^{29}$ when increased to $4-5 \mathrm{mg}$ analgesia may last up to 20 hours. ${ }^{17}$ Superior analgesia may be obtained with higher doses ranging from $4 \mathrm{mh}$ to $5 \mathrm{mg} .{ }^{17,24}$ After reaching $4 \mathrm{mg}$, adequate analgesia may be maintained by administering $0.5 \mathrm{mg}$ every 12 hours. ${ }^{20}$ Efficacy of route of administration also varies in preference as it is not constant among patients with some claiming better analgesia from oral administration and others from IV. ${ }^{15}$ 


\section{Levorphanol and Methadone}

Levorphanol and methadone are both inherently long-acting opioids that share multiple pharmacological similarities. They mechanisms of action include agonistic activity at the different opioid receptors $(\mu, \delta, \kappa)$, noncompetitive antagonism at the N-methyl-d-aspartate receptor (NMDA$\mathrm{R})$ and inhibition of serotonin (5-HT) and norepinephrine (NE) reuptake. ${ }^{18,30}$ All of these receptors systems may have analgesic efficacy.

Levorphanol's affinity to opioid and NMDA receptors (expressed in $\mathrm{Ki}$ and or $\mathrm{nM}$ value) is greater than that of methadone. Levorphanol is a full Kappa-receptor agonist with higher affinity at the Kappa-1 and Kappa-3 subtypes when compared to methadone, with Kappa-3 thought to be the main subtype involved in the analgesic effect. Levorphanol is similar to fentanyl in that it does not induce activation of ATP-sensitive $\mathrm{K}+$ channels whereas methadone does. $^{30}$

One of the greatest differences between these medications is their pharmacokinetic and side effect profiles. Methadone requires metabolism by hepatic CYP 450 enzymes whereas levorphanol does not. Moreover, there is pharmacogenomic variance in patients that may extend methadone's half-life to over 60 hours compared to levorphanol's average half-life of 11-16 hours that is not affected by pharmacogenomics. Methadone is implicated in QT-segment prolongation and patients with lower genetically related CYP2B6 activity will have increased risk of dysrhythmias. ${ }^{30}$

Levorphanol has a more predictable pharmacological profile when compared to methadone and according to some studies may cause fewer side effects than shorteracting opioids that are commonly used in modern practice. ${ }^{10,22,23}$ Despite levorphanol's shorter half-life, its analgesic duration of action is longer. In addition, its pharmacokinetic profile seems to limit drug-drug interactions while providing longer analgesia with decreased need for adjuvant analgesics. ${ }^{30}$

\section{Limitations and Future Directions in Research}

There are still many questions to be answered with regards to the use of levorphanol in the perioperative setting. In the United States, levorphanol is limited to oral formulation with no parenteral formulations currently available. This fact would limit the options for administration of this medication during the preoperative and postoperative periods. International availability of parenteral formulations would allow for use as an intraoperative analgesic. Studies concerning the use of levorphanol as premedication often fail to describe analgesic outcomes in the postoperative period, but additional study may be warranted given that these studies were not performed in the modern era of multimodal analgesia nor with current surgical techniques.

Methodology description is frequently ambiguous in early literature and statistical analysis is seldom mentioned in any of the studies reviewed from the 50's, 60's and 70's. As such, the validity and power of studies may be called into question. Current literature regarding levorphanol focuses on its use as a tool in chronic pain management and controlled trials in the perioperative setting are limited. Given recent interest in the use of methadone for perioperative pain management, there is potential for further research with levorphanol as a safer long acting opioid alternative (31). This would require prospective studies of levorphanol in the context of current multimodal analgesia strategies and enhanced recovery protocols.

\section{Conclusion}

Levorphanol is a long acting opioid with activity at multiple analgesic receptors similar to methadone. Older literature seems to indicate that levorphanol can be used throughout all phases of surgery in a safe and effective manner. This review of the available perioperative literature suggests that the use of this medication in the intraoperative or postoperative period can provide longer and improved postoperative analgesia when compared to short acting opioids and similar medications such as methadone. ${ }^{8-11}$ In doing so, total opioid requirements in the perioperative setting are decreased and risk for chronic opioid use beyond the operative period may be minimized. Its pharmacological properties, which include limited drug-drug interaction and increased safety profile, as compared to methadone, are important for its consideration both for future research and use as the opioid component of multimodal analgesic regimens.

\section{Disclosure}

The authors report no conflicts of interest for this work.

\section{References}

1. Brummett CM, Waljee JF, Goesling J, et al. New persistent opioid use after minor and major surgical procedures in US adults. JAMA Surg. 2017;152(6):e170504. doi:10.1001/jamasurg.2017.0504

2. Hill MV, Stucke RS, Billmeier SE, Kelly JL, Barth RJ Jr. Guideline for discharge opioid prescriptions after inpatient general surgical procedures. J Am Coll Surg. 2018;226(6):996-1003. doi:10.1016/j. jamcollsurg.2017.10.012 
3. Wu CL, King AB, Geiger TM, et al. American society for enhanced recovery and perioperative quality initiative joint consensus statement on perioperative opioid minimization in opioid-naive patients. Anesth Analg. 2019;129(2):567-577. doi:10.1213/ANE.0000000000004194

4. Stone AB, Wick EC, Wu CL, Grant MC. The US opioid crisis: a role for enhanced recovery after surgery. Anesth Analg. 2017;125 (5):1803-1805. doi:10.1213/ANE.0000000000002236

5. Jebaraj B, Ramachandran R, Rewari V, et al. Feasibility of dexmedetomidine as sole analgesic agent during robotic urological surgery: a pilot study. J Anaesthesiol Clin Pharmacol. 2017;33(2):187-192.

6. Parsa FD, Cheng J, Stephan B, et al. Bilateral breast reduction without opioid analgesics: a comparative study. Aesthet Surg J. 2017;37 (8):892-899. doi:10.1093/asj/sjx038

7. Bakan M, Umutoglu T, Topuz U, et al. Opioid-free total intravenous anesthesia with propofol, dexmedetomidine and lidocaine infusions for laparoscopic cholecystectomy: a prospective, randomized, double-blinded study. Rev Bras Anestesiol. 2015;65(3):191-199. doi:10.1016/j.bjan.2014.05.006

8. Dundee JW, Brown SS, Hamilton RC, McDowell SA. Analgesic supplementation of light general anaesthesia. A study of its advantages using sequential analysis. Anaesthesia. 1969;24(1):52-61. doi:10.1111/j.1365-2044.1969.tb02805.x

9. McDowell SA, Dundee JW. Neurolept anaesthesia: a comparison with a conventional technique for major surgery. Can Anaesth Soc J. 1971;18(5):541-551. doi:10.1007/BF03026016

10. Hunt RD, Foldes FF. The use of levo-dromoran tartrate (levorphan tartrate) for relief of postoperative pain. $N$ Engl J Med. 1953;248 (19):803-805. doi:10.1056/NEJM195305072481902

11. Morrison JD, Loan WB, Dundee JW. Controlled comparison of the efficacy of fourteen preparations in the relief of postoperative pain. Br Med J. 1971;3(5769):287-290. doi:10.1136/bmj.3.5769.287

12. Murphy GS, Szokol JW. Intraoperative methadone in surgical patients: a review of clinical investigations. Anesthesiology. 2019;131(3):678-692. doi:10.1097/ALN.0000000000002755

13. Randall LO, Lehmann G. Analgesic action of 3-hydroxy-N-methyl morphinan hydrobromide (dromoran). J Pharmacol Exp Ther. 1950;99(2):163-170.

14. Prommer E. Levorphanol: revisiting an underutilized analgesic. Palliat Care. 2014;8:7-10.

15. Braenden OJ, Eddy NB, Halbach H. Synthetic substances with morphine-like effect; relationship between chemical structure and analgesic action. Bull World Health Organ. 1955;13(6):937-998.
16. Dixon R, Crews T, Inturrisi C, Foley K. Levorphanol: pharmacokinetics and steady-state plasma concentrations in patients with pain. Res Commun Chem Pathol Pharmacol. 1983;41(1):3-17.

17. Rankin J, Mehnert J, Curreri AR. Effect of levallorphan tartrate on levorphanol tartrate analgesia in postoperative patients. AMA Arch Surg. 1957;74(4):602-605. doi:10.1001/archsurg.1957.01280100120021

18. Gudin J, Fudin J, Nalamachu S. Levorphanol use: past, present and future. Postgrad Med. 2016;128(1):46-53. doi:10.1080/00325 481.2016.1128308

19. Loitman JE. Levorphanol \#240. J Palliat Med. 2011;14(7):875-876. doi:10.1089/jpm.2011.9673

20. Brown AK. Levorphan in anaesthesia. Br Med J. 1954;2 (4894):967-969. doi:10.1136/bmj.2.4894.967

21. Starke J. Ars Medici (Liestal). Vol. 44. 1954:54.

22. Morrison JD, Loan WB, Dundee JW, McDowell SA, Brown SS. Studies of drugs given before anaesthesia. 18. The synthetic opiates. $B r \quad J$ Anaesth. 1969;41(11):987-993. doi:10.1093/bja/ 41.11.987

23. Dundee JW, Loan WB, Morrison JD. Studies of drugs given before anaesthesia XIX: the opiates. Br J Anaesth. 1970;42(1):54-58. doi:10.1093/bja/42.1.54

24. Stoelting VK, Theye RA, Graf JP. The use of dromoran hydrobromide (3-hydroxy-n-methylmorphinan hydrobromide) for preoperative medication. Anesthesiology. 1951;12(2):225-229. doi:10.1097/ 00000542-195103000-00008

25. Crehan A. Methorphinan as a supplementary anaesthetic medium J Ir Med Assoc. 1954;34(201):74-75.

26. Brotman M, Cullen SC, Wilkins DS. Intravenous supplementation during nitrous oxide anesthesia: comparison of demerol, morphine and a new potent analgesic drug (15431). Anesthesiology. 1950;11 (5):527-537. doi:10.1097/00000542-195009000-00002

27. Glazebrook AJ. Actions and uses of methorphinan. Br Med J. 1952;2 (4798):1328-1330. doi:10.1136/bmj.2.4798.1328

28. Banister EH. Six potent analgesic drugs. A double-blind study in post-operative pain. Anaesthesia. 1974;29(2):158-162. doi:10.1111/ j.1365-2044.1974.tb00614.x

29. Bozza M. N-methylmorphinan as adjuvant in nitrous oxide-oxygenpentothal anesthesia. Minerva Chir. 1954;9(7):319-327.

30. Pham TC, Fudin J, Raffa RB. Is levorphanol a better option than methadone? Pain Med. 2015;16(9):1673-1679. doi:10.1111/ pme. 12795
Journal of Pain Research

\section{Publish your work in this journal}

The Journal of Pain Research is an international, peer reviewed, open access, online journal that welcomes laboratory and clinical findings in the fields of pain research and the prevention and management of pain. Original research, reviews, symposium reports, hypothesis formation and commentaries are all considered for publication. The manuscript management system is completely online and includes a very quick and fair peer-review system, which is all easy to use. Visit http:// www.dovepress.com/testimonials.php to read real quotes from published authors. 